\title{
DROSOPHILA POLYRIBOSOMES
}

\author{
The Characterization of Two Populations by \\ Cell Fractionation and Isotopic Labeling \\ with Nucleic Acid and Protein Precursors
}

R. A. BOSHES

From the Department of Biology, University of Chicago, Chicago, Illinois 60637. Dr. Boshes's present address is Department of Molecular Biophysics and Biochemistry, Yale University, New Haven, Connecticut 06520

\begin{abstract}
Two populations of polyribosomes have been isolated from third instar larvae of $D$. melanogaster. One population appeared to be soluble while the second seemed membranebound. Short-term labeling of the two RNP fractions with radioactive nucleic acid and protein precursors was achieved by using a feeding stimulant. RNA was extracted from both polyribosomal fractions following 25,40 , and $60 \mathrm{~min}$ of in vivo uridine ${ }^{3} \mathrm{H}$ incorporation. Soluble polyribosomes exhibited more rapid uptake of uridine into ribosomal and heterogeneous RNA fractions than did membrane-bound polyribosomes at comparable time periods. In vivo amino acid incorporation into the two polyribosomal populations was examined after $10,20,40,60$, and $80 \mathrm{~min}$ of incubation in leucine- ${ }^{3} \mathrm{H}$. In this case, the membrane-bound polyribosomes reached a higher specific activity than did the soluble ones. These functional differences confirmed the observation, based on cellular fractionation studies, that the two classes of polyribosomes represented functionally distinct populations. These data have been compared with those from studies on other metazoan systems. In addition, dithiothreitol has been demonstrated to be a powerful ribonuclease inhibitor.
\end{abstract}

\section{INTRODUCTION}

Combining biochemical with genetic analysis to elucidate mechanims of regulating protein synthesis has been highly successful in prokaryotes and certain eukaryotic systems. Drosophila melanogaster needs no introduction as an organism suitable for correlated biochemical and genetic studies (Ephrussi, 1942; Ritossa and Spiegelman, 1965; Ritossa and Atwood, 1966; Ritossa, Atwood, and Spiegelman, 1966a and b; Hennig, 1968). In order to utilize Drosophila for investigating the molecular basis of development and differentiation, it is essential to understand the regulation of protein synthesis and, concomitantly, the biochemistry of those RNA ${ }^{1}$ and RNP moieties involved in protein synthesis.

This report describes the isolation of soluble and

\footnotetext{
${ }^{1}$ Abbreviations: RNA, ribonucleic acid; DNA, deoxyribonucleic acid; RNP, ribonucleoprotein; DTT, dithiothreitol-Gleland's Reagent; r-RNA, ribosomal-RNA; m-RNA, messenger-RNA; t-RNA, transfer RNA; RNase, ribonuclease; SDS, sodium dodecyl sulphate; EDTA, ethylenediamenetetraacetic acid; TCA, trichloroacetic acid; DOC, sodium deoxycholate.
} 
membrane-bound polyribosomes from larvae of Drosophila. In addition, a method has been developed for rapidly labeling larval RNA and protein. Short-term incorporation of uridine into the RNA's of the two polyribosomal fractions has been investigated. Different rates of synthesis of the several classes of RNA's suggests an operational distinction between soluble and membranebound polyribosomes. Moreover, in vivo amino acid incorporation studies in both polyribosome preparations support this functional distinction between membrane-bound and soluble populations.

\section{MATERIALS AND METHODS}

\section{Fly Culturing}

Stocks of D. melanogaster Oregon R. were raised under standard laboratory conditions on a modified version of Carpenter's yeast-agar medium (1950).

STERILE CULTURE : All radioactive incorporation studies have been conducted with axenic cultures. With short-term radioactive labeling of RNA from nonsterile cultures, the bulk of uridine $-{ }^{3} \mathrm{H}$ appeared in size classes of r-RNA (23S and 16S) characteristic of prokaryotic organisms. Only after $24 \mathrm{hr}$ did the radioactivity cosediment with the optical density peaks. On the other hand, 16S and 23S peaks never appeared in rapidly labeled axenic larvae (Boshes, 1969).

Laboratory cultures of Drosophila were made aseptic following the protocol of Horikawa and Fox (1964). The dechorionated, sterilized eggs, collected on Whatman GF/A glass filter pads (Arthur H. Thomas Co., Philadelphia, Pa.), were transferred aseptically to sterile food vials (see below) and maintained at $25^{\circ} \mathrm{C}$ in a sterile chamber. Following eclosion, the flies were transferred to other sterile vials every $48 \mathrm{hr}$. Eight separate lines were maintained in this fashion. To assay for contamination, contents of used culture vials were periodically plated on three different growth media: Wort agar, pH 4.8 (Fisher Scientific Co., Chicago, Ill.), selects for molds and yeast; tryptone glucose extract agar, $\mathrm{pH} 7.0$, is a general bacterial medium; and Sabourraud's dextrose agar, $\mathrm{pH} 5.6$, selects for mold and aciduric bacteria. (The latter two media are from Difco Laboratories, Detroit, Mich.) Mold was suppressed by occasionally raising a generation of flies on medium containing $1 \%$ crystal violet (Cooper, 1968). As noted by Church and Robertson (1966), the development of larvae is retarded for 24-48 hr under these conditions, apparently owing to the absence of live yeast.

Axenic flies were cultured on sterilized modified Carpenter's medium. $1 \mathrm{ml}$ of Tegosept solution
(10\% Tegosept powder [Goldschmidt Chemical Co., New York] dissolved in $95 \%$ ethanol) was added to $100 \mathrm{ml}$ of medium to inhibit mold. To inhibit bacteria, penicillin-streptomycin (Microbiological Associates, Inc., Bethesda, Md.), final concentration 100 units $/ \mathrm{ml}$ penicillin and 100 units $/ \mathrm{ml}$ streptomycin, was included.

RADIOACTIVE LABELING: Taking into account that Drosophila larvae are particulate feeders, they were incubated in either $0.50 \mathrm{ml}$ of uridine $-5-{ }^{3} \mathrm{H}$ $(20.0 \mathrm{c} / \mathrm{mm}$ le, Schwarz BioResearch, Orangeburg, N.Y.) or $0.50 \mathrm{ml}$ of L-leucine $-4,5-{ }^{3} \mathrm{H}(30-50 \mathrm{c} / \mathrm{mmole}$, New England Nuclear, Boston, Mass.) containing $0.02 \mathrm{~g}$ of autoclaved dried brewer's yeast (Standard Brands, New York) which stimulates feeding. In this yeast-isotope mixture, larvae could be maintained for as long as $96 \mathrm{hr}$, and they could pupate normally.

\section{Extraction Procedures- \\ Ribonucleoprotein Particles}

ISOLATION OF TOTAL POIYRIBOSOMAL POPULATION: Larvae were collected by dispersing the masticated Carpenter's medium in water and pouring the slurry into a large beaker. The larvae sank while the small food particles, dead adults, and pupae remained in suspension. After repeatedly decanting the debris, the larvae were collected by filtration on a Buchner funnel and weighed. Typically, $0.4 \mathrm{~g}$ of third instar larvae was suspended in $8 \mathrm{ml}$ of solution A containing $0.01 \mathrm{M} \mathrm{MgCl}_{2}, 0.01 \mathrm{M}$ Tris-HCl (pH 7.6), 0.05 м KCl, 0.004 м DTT (Cal Biochemical Company, Pasadena, Calif), to which were added 0.25 м sucrose (ribonuclease-free from Schwarz BioResearch Company) and 1\% Triton X-100 (Rohm and Hass, Philadelphia, Pa.). This suspension was homogenized at $4^{\circ} \mathrm{C}$ in a Dounce tissue grinder (Allfrey, 1959) with 20 strokes of the loosefitting $A$ ball. A ratio of $20 \mathrm{ml}$ of homogenization buffer $/ \mathrm{g}$ of filter-dried larvae is optimal. The ratio permits fairly rapid homogenization, and it yields adequate material for optical density and radioactive labeling studies. The homogenate was centrifuged at $10,000 \mathrm{~g}$ in the 50 rotor of the Spinco Model L ultracentrifuge (Beckman Instruments, Inc., Palo Alto, Calif.) for $30 \mathrm{~min}$. The $8 \mathrm{ml}$ of supernatant was then divided in half and layered on the following step gradients : $3 \mathrm{ml}$ of $0.5 \mathrm{M}$ sucrose in solution A layered over $2 \mathrm{ml}$ of $1.5 \mathrm{M}$ sucrose in solution $\mathrm{A}$. The tubes were centrifuged in $10 \mathrm{ml}$ polypropylene tubes at $105,000 \mathrm{~g}$ for $150 \mathrm{~min}$ in the 50 rotor. The supernatant was carefully poured off, and the walls were wiped dry with paper. The pellet which contained both populations of polyribosomes was then gently resuspended in $1 \mathrm{ml}$ of solution A without DTT.

ISOLATION OF NONSEDIMENTABLE (SOLUBLE) AND SEDIMENTABLE (MEMBRANE-BOUND) POLY- 
RIвоsomes: Soluble polyribosomes were recovered by homogenizing larvae in $0.25 \mathrm{M}$ sucrose in solution A with no Triton X-100. To disrupt the cells in the absence of detergent, this preparation must be rehomogenized with five strokes of the tightfitting $B$ ball after treatment with the $A$ ball. Following a $10,000 \mathrm{~g}$ centrifugation, Triton $\mathrm{X}-100$ was added to bring the supernatant to a final concentration of $1 \%$. The $10,000 \mathrm{~g}$ pellet was rehomogenized with $8 \mathrm{ml}$ of $0.25 \mathrm{M}$ sucrose in solution A containing $1 \%$ Triton X-100. Ten strokes of the $A$ ball was followed by another $10,000 \mathrm{~g}$ centrifugation. Both supernatants were layered over sucrose step gradients, centrifuged, and the RNP pellets were resuspended as previously described for total polyribosomes.

\section{Extraction Procedure-Ribonucleic Acid}

BULK RNA : Total RNA was extracted and deproteinized according to a modification of the method described by Ritossa and Spiegelman (1965). $0.004 \mathrm{M}$ DTT was added to all solutions in place of $0.001 \%$ sodium heparin as a ribonuclease inhibitor. Yields of RNA ranged from 70 to $115 \mathrm{OD}_{254}$ units/g wet weight of larvae. Drosophila bulk RNA $\mathrm{E}_{254}^{1 \%}$ equals 200 (Boshes, 1969), indicating a yield of 3.5-5.6 mg bulk RNA/g wet weight of tissue. Church and Robertson (1966) found in their biochemical study that wet weight of $D$. melangaster is a valid parameter for standardizing data for comparison.

RNA EXTRACTED FROM POLYRIBOSOMAL FRACTIONS: RNA was extracted from polyribosome-containing superantants by utilizing a modification of Penman's method for extracting RNA from HeLa nuclei (1966). Each supernatant was made $1 \%$ with SDS (Fisher Scientific Co.), homogenized in a Potter-Elvehjem grinder fitted with a Teflon pestle (Allfrey, 1959), and extracted with an equal volume of phenol saturated with a modified "high salt" buffer containing $0.5 \mathrm{~m} \mathrm{NaCl}, 0.005 \mathrm{M}$ $\mathrm{MgCl}_{2}$, and $0.004 \mathrm{M}$ DTT, $\mathrm{pH}$ adjusted to 5.1 with $0.01 \mathrm{M}$ acetate buffer. The RNA was further deproteinized and isolated as described by Ritossa and Spiegelman (1965).

\section{Analyses}

SUGROSE DENSITY GRADIENTS: RNA and polyribosomes were analyzed on either linear or exponential sucrose density gradients. Linear gradients for polyribosomes consisted of $14.5 \mathrm{ml}$ of $1.5 \mathrm{M}$ sucrose in solution A (minus DTT) and $15 \mathrm{ml}$ of $0.5 \mathrm{~m}$ sucrose in solution A (minus DTT). The gradients were precooled for a minimum of $2 \mathrm{hr}$ before centrifugation. Polyribosomes were centrifuged for $2 \mathrm{hr}$ at $25,000 \mathrm{rpm}$ in the SW 25.1 rotor of the Spinco Model $\mathrm{L}$ at $4^{\circ} \mathrm{C}$. The tubes were fractionated by means of the ISCO density gradient fractionator (Instrumentation Specialties Co., Lincoln, Neb.), and their optical density at $254 \mathrm{~m} \mu$ was recorded through an ISCO UV analyzer. Fractionation was performed at $2 \mathrm{ml} / \mathrm{min}$, and $1 \mathrm{ml}$ fractions were collected. To calibrate the UV analyzer chart, several tubes from the gradient, selected at points where the absorbance tracing is not inflecting, were read in the Zeiss PMQ II spectrophotometer at $254 \mathrm{~m} \mu$ against a blank of appropriate buffer.

Convex exponential gradients were made according to the procedure of Noll (1967), using 0.5 $M$ sucrose in solution A and $1.25 \mathrm{M}$ sucrose in solution A. The highest concentration of sucrose in the gradient was $1.0 \mathrm{M}$. Exponential gradients were spun for $2.5 \mathrm{hr}$ at $25,000 \mathrm{rpm}$ in the SW 25.1 rotor.

RNA was centrifuged on linear sucrose density gradients in buffer containing $0.1 \mathrm{~m} \mathrm{NaCl}$ and 0.01 $\mathrm{M}$ acetate adjusted to $\mathrm{pH} 5.1$. The sucrose concentrations ranged from 0.5 to $0.125 \mathrm{M}$. RNA was centrifuged at either $23,000 \mathrm{rpm}$ for $16 \mathrm{hr}$ or 25,000 rpm for $12 \mathrm{hr}$ at $4^{\circ} \mathrm{C}$ in the SW 25.1 rotor. In all linear gradients, sedimentation values have been assigned according to the procedure of Martin and Ames (1961) for comparing an unknown peak to a known standard with similar sedimentation properties. Hastings and Kirby (1966) reported $S_{20, w}$ values of $29.4 \mathrm{~S}$ and $18.8 \mathrm{~S}$ for the major components of Drosophila ribosomal RNA. The majority of $r-\mathrm{RNA}$ from eukaryotic material has been assigned sedimentation constants of 28 and 18S. These latter values are used for ease of comparison. The nominal 28S r-RNA peak has been used as the referent peak in calculating $S$ values of other peaks.

For purposes of comparing specific activities (dpm's/OD 254 ) of RNA fractions between and within the several RNP populations, the preparation and collection of sucrose gradients were standardized. In nearly all cases, RNA greater than $28 \mathrm{~S}$ includes tubes 32-23, 28S r-RNA includes tubes 22-16, and 18S r-RNA includes tubes 15-9, heterogeneous RNA includes tubes $8-5$, and $4 \mathrm{~S}$ RNA includes tubes 4-1.

RNASE DIGESTION: Polyribosomal preparations were treated with crystalline pancreatic RNase A (Worthington Biochemical Co., Freehold, N.J.). The RNA, dissolved in solution A without DTT, was treated for $20 \mathrm{~min}$ at $4{ }^{\circ} \mathrm{C}$ with 37.4 units $(10$ $\mu \mathrm{g}$ ) of RNase/ml.

RADIOAGTIVE GOUNTING: All samples of homogenized tissue, RNP, or RNA preparations were precipitated by adding $30 \%$ ice-cold TCA to a final concentration of $5 \%$. The precipitate was collected on $2.4 \mathrm{~cm} \mathrm{GF} / \mathrm{A}$ glass filters and measured by liquid scintillation counting in a toluene-based flour. All counts were converted to disintegrations by using the Channel's ratio method to estimate efficiency of counting.

KINETIC STUDIES OF LEUCINE- ${ }^{3}$ H INCORPO- 
RATION INTO POLYRIBOSOMAL FRAGTIONS : In order to study the kinetics of amino acid incorporation into the two polyribosomal fractions, larvae were incubated in leucine- ${ }^{3} \mathrm{H}$; aliquots were removed after $10,20,40$, and $80 \mathrm{~min}$; and these samples were fractionated. Free and membrane-bound polyribosome-containing supernatants were layered on step gradients and centrifuged for $2.5 \mathrm{hr}$ at $105,000 \mathrm{~g}$ as described above. The polyribosomal pellets, as well as the supernatants from the step gradient, were recovered. The pellets were redissolved in buffer, read at $254 \mathrm{~m} \mu$ in the Zeiss PMQ II spectrophotometer, and counted for radioactivity as described above. The supernatants through which these RNP aggregates had sedimented were also counted for radioactivity, providing an indicator of cumulative protein labeling. The relative activities of the supernatants were normalized to their respective RNP pellets, in order to compare the changes in supernatant activities at the several time points (see Fig. 7). Cytoplasmic proteins are a potential contamination of isolated RNP pellets and could confuse the data on incorporation into the RNP. If a constant percentage of contaminating cellular protein became associated with each RNP pellet isolated in the course of the kinetic study, newly synthesized cytoplasmic proteins would be contribuing progressively more radioactivity with time. By monitoring relative activity in both supernatants which contain these discharged proteins, radioactivity specifically associated with the two RNP pellets could be estimated.

\section{RESULTS}

\section{Analysis of Polyribosome Isolation}

TOTAL POLYRIBOSOMAL EXTRACTION: Fig. I exhibits polyribosomes isolated from $D$. melanogaster by homogenizing larvae in buffer containing Triton $\mathrm{X}-100$. This procedure enhanced the recovery of polyribosomes relative to monosomes by eliminating a mechanical homogenization step-grinding with the tight-fitting $B$ ball. (cf. Figs. 1 and 2.). The yield of ribonucleoprotein from such preparations was similar to that of RNA

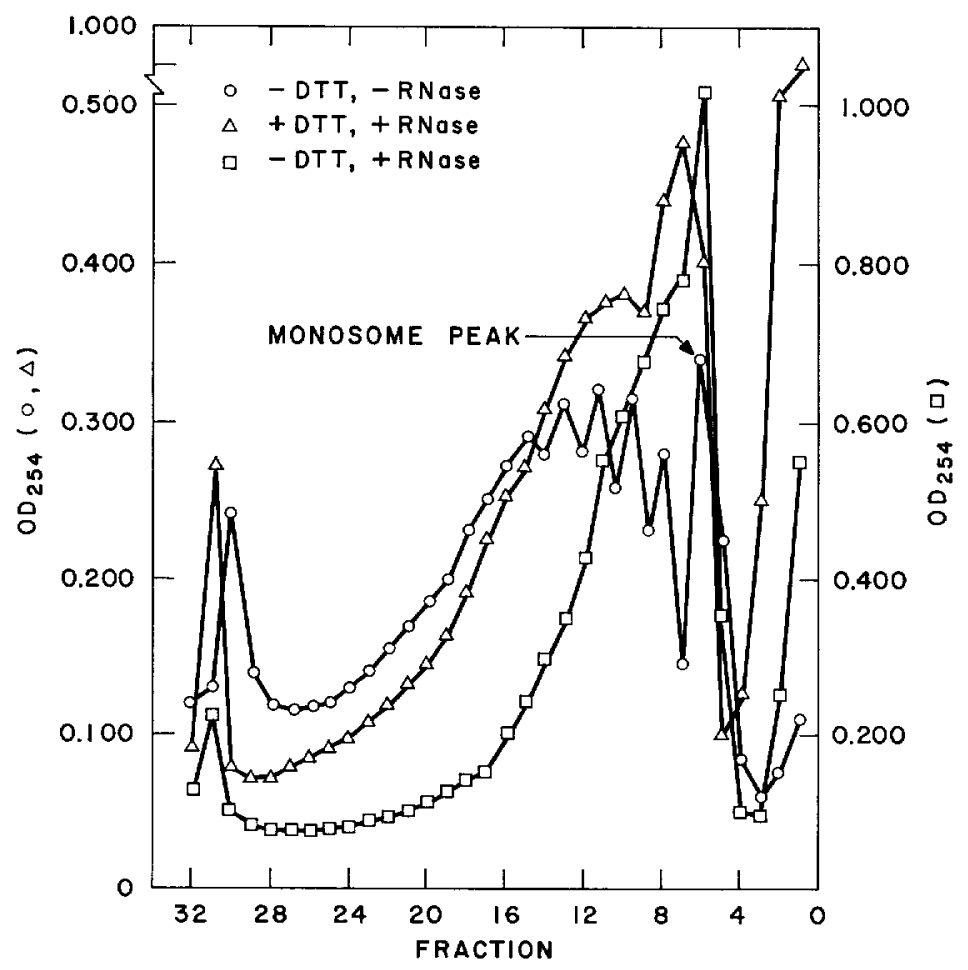

Figure 1 Sedimentation profiles of total polyribosomes from $D$. melanogaster treated with RNase in the presence and absence of $0.004 \mathrm{M}$ DTT. The RNP was extracted and purified as described in Materials and Methods. The polyribosomes were analyzed on $0.5-1.0 \mathrm{M}$ sucrose linear density gradients containing solution A. 0.004 м DTT was present or absent as indicated. Centrifugation was at $4^{\circ} \mathrm{C}$ for $2 \mathrm{hr}$ at $25,000 \mathrm{rpm}$ in a Spinco SW 25.1 rotor. Optical density was continuously monitored at $254 \mathrm{~m} \mu$. 


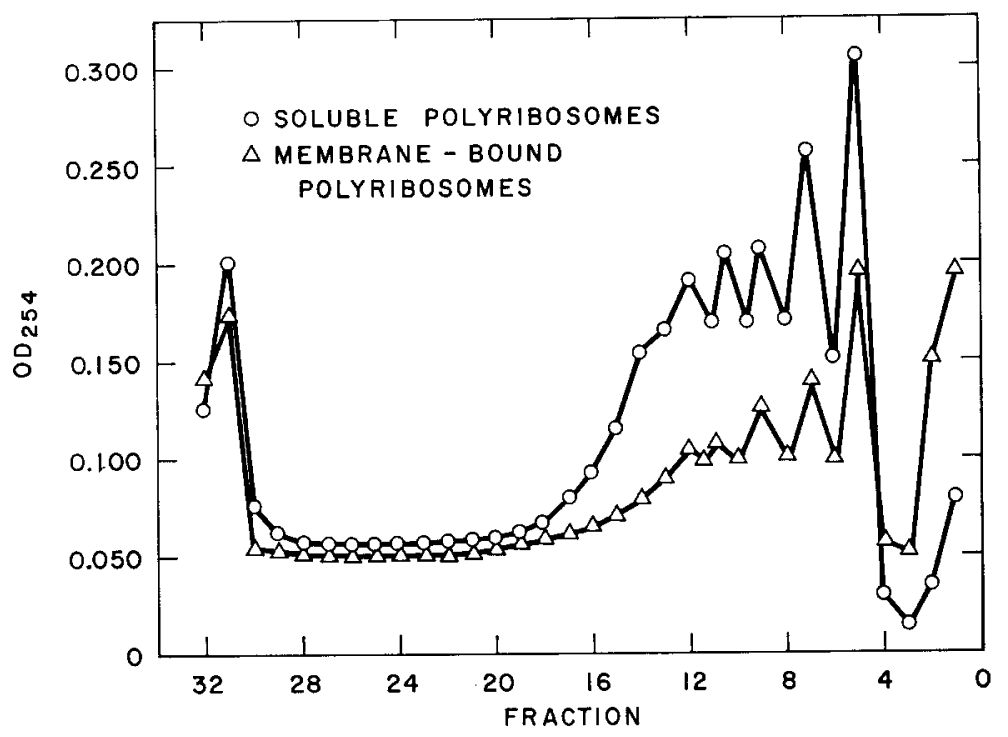

FigURE 2 Sedimentation profiles of soluble and membrane-bound polyribosomes from $D$. melanogaster larvae. The two polyribosomal fractions were extracted and purified as described in Materials and Methods and exhibit the effect of more extensive mechanical disruption. The polyribosomes were analyzed on sucrose linear density gradients as described in Materials and Methods. Optical density was continuously monitored at $254 \mathrm{~m} \mu$.

recovered from the ribosomal components of a bulk RNA isolation. $54 \mathrm{OD}_{254}$ units/g larvae were recovered from the gradients illustrated in Fig. 1, nearly $3 \mathrm{mg} / \mathrm{g}$ tissue. A yield of $3 \mathrm{mg}$ $\mathrm{r}$-RNA/g larvae is typical for cold-phenol-extracted bulk RNA (Boshes, 1969; Ritossa and Spiegelman, 1965).

EXTRACTION OF SOLUBLE AND MEMBRANE-BOUND POLYRIBOSOMES: Sequentially extracted soluble and membrane-bound polyribosomes are shown in Fig. 2. Both profiles exhibit the effects of more extensive mechanical manipulations. The yield of RNP from the two profiles in Fig. 2 was $3.2 \mathrm{mg} \mathrm{RNP} / \mathrm{g}$ larvae, which is similar to total polyribosome extractions. Following homogenization in the absence of Triton $\mathrm{X}-100$, the first $10,000 \mathrm{~g}$ supernatant contained one soluble, "nonsedimentable" polyribosome fraction. A gentle rehomogenization of the first $10,000 \mathrm{~g}$ pellet in the presence of detergent yielded a second polysome population. This second polysome class was considered to be membrane-bound on the basis of the following criteria: (a) it sedimented during the initial homogenization procedure; $(b)$ it was solubilized by detergent, and $(c)$ electron microscopic examination of the initial pellet showed the presence of ribosomes bound to membrane (Boshes, 1969).
RNASE TREATMENT OF POLYRIBOSOMES: Fig. 1 exhibits polyribosomes treated with RNase $\mathrm{A}$ in the presence and absence of $0.004 \mathrm{M}$ DTT to illustrate the efficacy of the latter as an RNase inhibitor. The definition of the several RNP classes has been somewhat obscured by RNase treatment, but the over-all ratio of polysomes to monosomes is virtually unchanged. RNase exposure in the absence of DTT failed to degrade quantitatively polysomal aggregates to the monosome region, but did convert heavier polyribosomes to the $\mathrm{di}^{-}$, tri-, and tetrasome region of the gradient. The majority, however, did not appear under the monosome peak.

\section{Analysis of RNA Isolated from RNP Fractionation}

Ribosomal-RNA constituted $62 \%$ of the RNA recovered from the first $10,000 \mathrm{~g}$ supernatant (Fig. 3). However, the distribution of 28S:18S r-RNA was not typical of an RNA extraction from Drosophila. The expected relationship between the components should be $1.92: 1$, on the basis of measurements of Drosophila 28 and 18S r-RNA's having molecular weights of $1.40 \times 10^{6}$ and $0.73 \times 10^{6}$, respectively (Loening, 1968), and the two classes being present in equimolar amounts, 


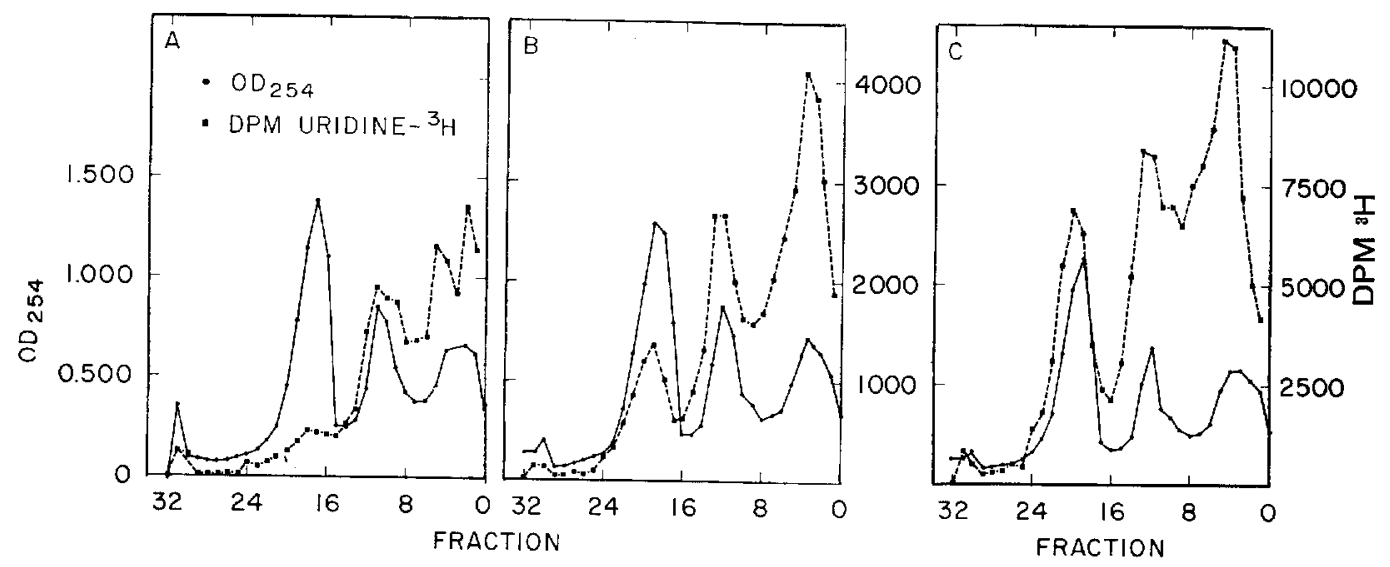

FigURE 3 Sedimentation profiles of RNA extracted from RNP recovered from first $10,000 \mathrm{~g}$ supernatant (soluble RNP) of fractionated D. melanogaster larvae incubated in uridine- ${ }^{3} \mathrm{H}$. RNA was analyzed on 0.125-0.5 м sucrose linear density gradients made up in solution A without DTT and centrifuged at $4^{\circ} \mathrm{C}$ for $16 \mathrm{hr}$ at $23,000 \mathrm{rpm}$ in a Spinco SW 25.1 rotor. Optical density was continuously monitored at $254 \mathrm{~m} \mu$. $1 \mathrm{ml}$ fractions were collected for counting as described in Materials and Methods. $3 \mathrm{~A}, 25$ min incubation; $3 \mathrm{~B}, 40 \mathrm{~min}$ incubation; $3 \mathrm{C}, 60 \mathrm{~min}$ incubation.

having been synthesized coordinately (Brown and Littna, 1964; Darnell, 1968). The observed ratio of 28S:18S of 1.57 ( $\mathrm{sE}= \pm 0.05$ ): 1 for the first supernatant was low in comparison with that from the membrane-bound population. The large $\mathrm{OD}_{254}$ peak in the $4 \mathrm{~S}$ region of the gradient (Fig. 3) accounted for nearly $19 \%$ of the RNA. Transfer RNA is thought to exist primarily as a free cytoplasmic constituent (Bernhardt and Darnell, 1969) and therefore should be associated with this fraction, but it has not been determined that this material is exclusively t-RNA.

In the second $10,000 \mathrm{~g}$ supernatant (Fig. 4) the r-RNA accounted for $63 \%$ of the total, making it nearly identical to the first population in this regard; but this population consistently contained a greater percentage of material in the $28 \mathrm{~S}$ region relative to the $18 \mathrm{~S}$ than did RNA extracted from the first supernatant. The $28 \mathrm{~S}: 18 \mathrm{~S}$ ratio was 2.01 ( $\mathrm{sE}= \pm .09$ ) $: 1$. The percentage of 4S RNA in this fraction, $10 \%$, was half of that recovered from the first $10,000 \mathrm{~g}$ supernatant.

\section{Uridine Incorporation into Polyribosomal Fractions}

Specific activity accretion of uridine-- ${ }^{3} \mathrm{H}$ into RNA from soluble and membrane-bound polyribosomes is exhibited in Fig. 5. In every case the two fractions were isolated from the same bath of larvae. Significantly more radioactivity per $\mathrm{OD}_{254}$ unit appeared in the soluble than in the membrane- bound population at comparable time periods. This difference provides another operational criterion for distinguishing membrane-bound from soluble polyribosomes.

Uridine- ${ }^{3} \mathrm{H}$ incorporation into the $4 \mathrm{~S}$ region was nearly identical in both populations (Figs. $5 \mathrm{~A}$ and $\mathrm{B}$ ). This similarity in $4 \mathrm{~S}$ specific activity between the two fractions is markedly contrasted by the other classes of RNA. These counts cannot be attributed to terminal cytidine labeling of transfer RNA since uridine cannot be converted to cytidine by Drosophila (Dr. Charles Laird, personal communication).

\section{Amino Acid Incorporation into Polyribosomal Fractions}

Fig. 6 demonstrates soluble and membranebound polyribosomes extracted from the same larvae following $60 \mathrm{~min}$ of incubation in leucine${ }^{3} \mathrm{H}$. The $\mathrm{OD}_{254}$ profile of the soluble fraction indicates that the material was either slightly degraded or disturbed in the fractionation procedure. However, the data are adequate for purposes of this discussion. The specific activities of amino acids incorporated into the polyribosomes were substantially higher in the membranebound than in the free population. The specific activities of the monosome regions were both lowless than $1000 \mathrm{dpm} / \mathrm{OD}_{254}$ in both populations. Lighter polyribosomes (tubes 7-19) of the membrane-associated fraction had twice the specific 


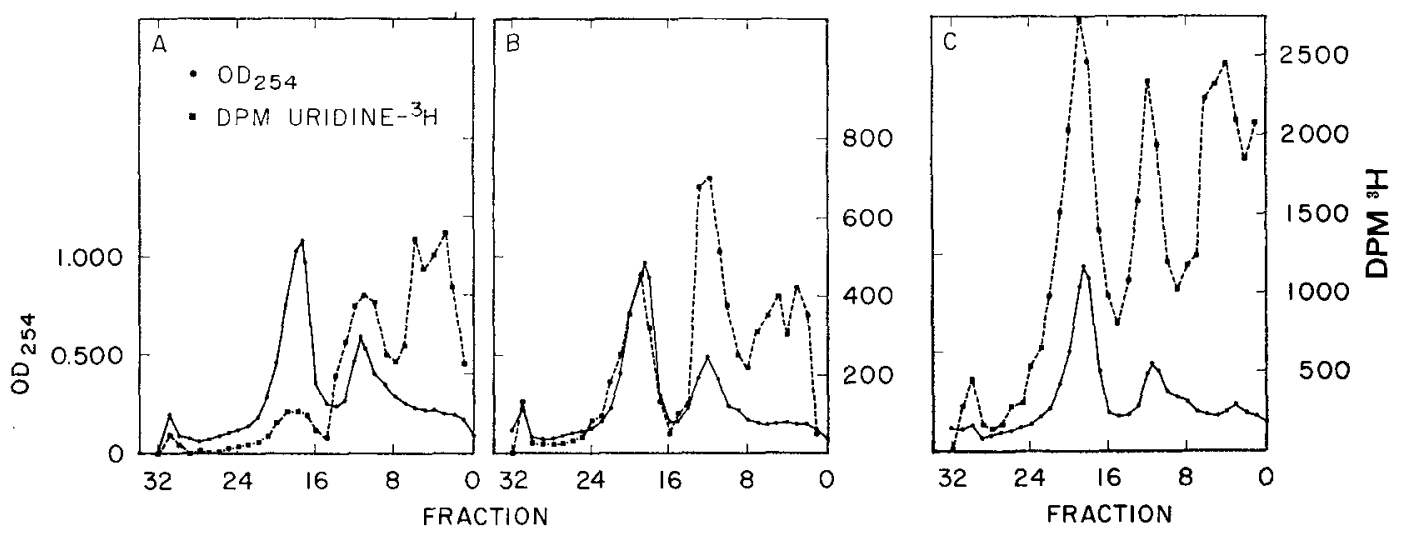

FIGURE 4 Sedimentation profiles of RNA extracted from RNP recovered from second $10,000 \mathrm{~g}$ supernatant (membrane-bound RNP) of fractionated D. melanogaster larvae incubated in uridine- ${ }^{3} \mathrm{H} .4 \mathrm{~A}, 25 \mathrm{~min}$ incubation; $4 \mathrm{~B}, 40 \mathrm{~min}$ incubation; $4 \mathrm{C}, 60 \mathrm{~min}$ incubation.

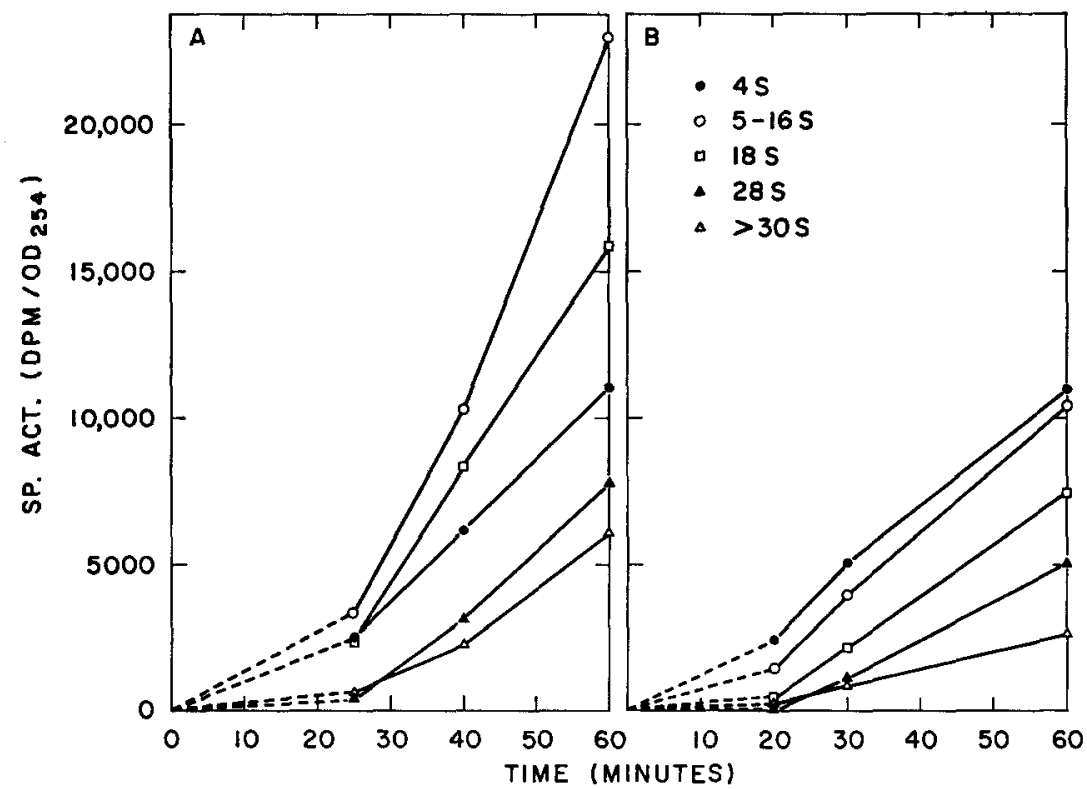

FIGURE 5 Specific activity accretion of different RNA populations isolated from $10,000 \mathrm{~g}$ supernatants of larvae incubated in uridine- ${ }^{3} \mathrm{H}$ for 25,40 , and $60 \mathrm{~min}$. (See Figs. 3 and 4 .) $5 \mathrm{~A}$, first $10,000 \mathrm{~g}$ supernatant containing soluble polyribosomes. $5 \mathrm{~B}$, second $10,000 \mathrm{~g}$ supernatant containing membrane-bound polyribosomes.

activity $\left(9700 \mathrm{dpm} / \mathrm{OD}_{254}\right)$ of comparable areas from the soluble fraction $\left(5033 \mathrm{dpm} / \mathrm{OD}_{154}\right)$. This region included aggregates up to approximately 10 ribosomes. The difference in specific activities in the very large polyribosome portion of the profiles was less than twofold.

Fig. 7 exhibits specific activity accretions of membrane-bound and soluble RNP pellets as well as net accumulation of TCA-precipitable counts into the respective supernatant fractions. These latter data reflect newly synthesized proteins in the cytoplasm.

Both polyribosomal fractions reached a steady state of amino acid incorporation by $40 \mathrm{~min}$ as evidenced by the plateaus in the curves of radioactive uptake. By this time, the membrane-bound fraction had approximately four times the specific activity of the soluble population. The supernatant 


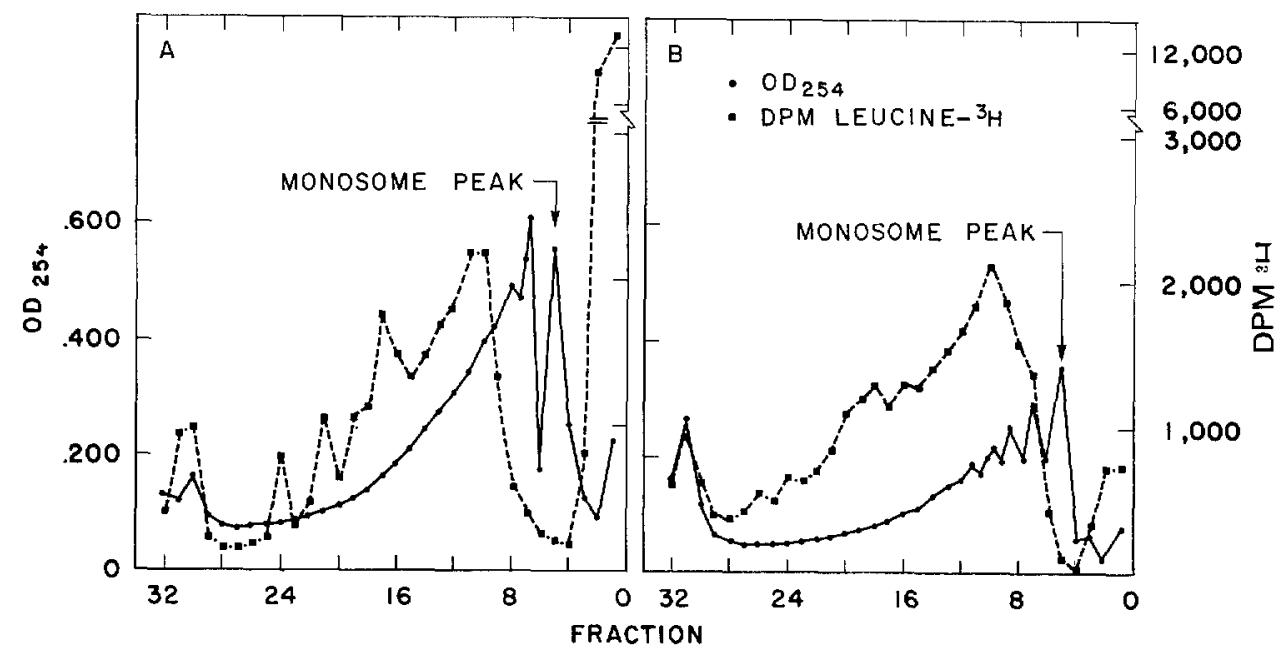

Figure 6 Sedimentation profiles of soluble and membrane-bound polyribosomes extracted from $D$. melanogaster larvae incubated for $60 \mathrm{~min}$ in leucine ${ }^{3} \mathrm{H} .6 \mathrm{~A}$, nonsedimentable, soluble, polyribosomes; $6 \mathrm{~B}$, sedimentable, membrane-bound, polyribosomes.

recovered from the membrane-bound RNP did not accumulate significant radioactivity until 20 min, indicating that label in membrane-bound RNP pellets was not artificial contamination of its associated supernatant.

After $40 \mathrm{~min}$, the step-gradient through which the membrane-bound polysomes had been pelleted contained over $85,000 \mathrm{dpm} / 50 \mu \mathrm{g}$ pelleted RNP, while the step-gradient of the soluble polysomes had $65,000 \mathrm{dpm} / 50 \mu \mathrm{g}$ pelleted RNP. By $80 \mathrm{~min}$, however, this supernatant had a higher specific activity than the comparable supernatant from the membrane-bound polyribosomes, in spite of the fact that these latter polyribosomes, which had pelleted through this less active supernatant, contained over three times the radioactivity of the soluble polysome pellets. These results suggest that the pelleted RNP's are not contaminating or being contaminated by supernatants of differing specific activites, and they provide further support for an operational distinction between the two populations of polyribosomes.

\section{DISCUSSION}

\section{Polyribosome Isolation}

EVALUATION OF METHODOLOGY: Criteria for evaluating a satisfactory polyribosome isolation procedure are not clearly defined. The primary criterion has been the proportion of aggregates of polyribosomes relative to monosomes, disomes, and trisomes, judged to be degradation products by many investigators (Warner et al., 1963; Wettstein et al., 1963; Rifkind et al., 1964). In this study the total yield of RNP relative to bulk RNA, as well as the quality of the optical density profile, have been monitored in evaluating the progress of the extraction procedure. In order to achieve the quantitative isolation of apparently undegraded polyribosomes, several modifications of previously published protocols were introduced. A Dounce tissue grinder was utilized to extract Drosophila polyribosomes without shearing damage. The concentration of $\mathrm{Mg}^{++}$had been set at $5 \mathrm{~mm}$ according to many published protocols. $10 \mathrm{~mm}$ $\mathrm{Mg}^{++}$was, however, essential for isolating large aggregates of Drosophila polyribosomes. Triton X-100 replaced DOC as the detergent since it appeared to be less injurious to Drosophila polyribosomes than ionic detergents.

While soluble and membrane-bound polyribosomes may be distinguished on the basis of isolation procedure and labeling characteristics, it is important to recognize the limitations of such distinctions. The soluble fraction is, in operational terms, a population of RNP that did not sediment after 30 min at $10,000 \mathrm{~g}$. Within this class may be polyribosomes which are truly soluble, polyribosomes attached to intact membranes whose entire structure is too light to sediment, and polyribosomes attached to originally heavy vesicles which have become nonsedimentable owing to disruption in the course of isolation. Sedimentable 


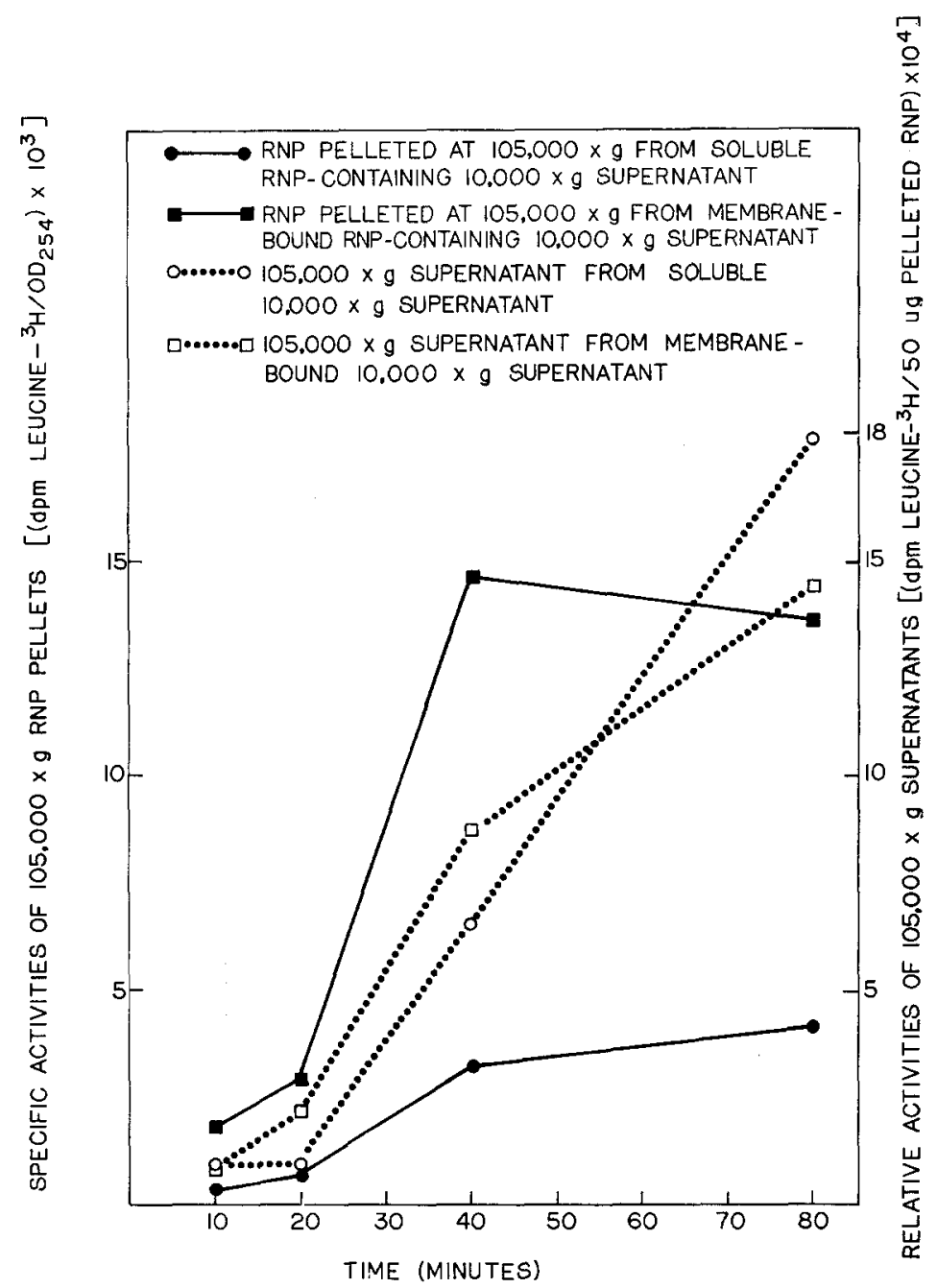

FIGURE 7 Specific activity accretion of soluble and membrane-bound RNP pellets and their supernatants following incubation in leucine ${ }^{-3} \mathrm{H}$. At $10,20,40$, and $80 \mathrm{~min}$, aliquots of larvae were removed and homogenized according to the procedure for recovering two populations of polyribosomes. The RNP pellets, which had been purified by sedimentation through a step gradient, were resuspended in solution A, read at $254 \mathrm{~m} \mu$, and counted for radioactivity. The step gradients, through which the RNP had been pelleted, were also counted for radioactivity.

polyribosomes, on the other hand, may contain polyribosomes bound to endoplasmic reticulum or secretory vesicles, as well as RNP associated with the nuclear envelope.

The possibility of finding functional relationships between soluble and membrane-bound polyribosomes is tempting in a study of this kind. However, these two populations of Drosophila polyribosomes might have been isolated from differing cell types. Drosophila secretory tissue such as the salivary gland and ring gland may contain different ratios of membrane-bound to soluble polyribosomes than other rapidly growing larval tissues or rapidly dividing imaginal disc tissue (Palade, 1959; Siekevitz and Palade, 1959; Redman and Sabatini, 1966a and b; Goldberg and Green, 1967).

RNASE STUDIES: DTT was selected as the RNase inhibitor of choice because it was highly effective in low concentration. Nuclease inhibitors such as sodium heparin or mercaptoethanol had been added in order to inhibit endogenous ac- 
tivity, but with no appreciable improvement. DTT, by virtue of the stability of the intramolecular disulfide bridge formed by oxidation, is a powerful sulfhydryl reducing compound, and hence a potent RNase inhibitor (Fig. 1). To the best of my knowledge, D'TT has not previously been recognized as a ribonuclease inhibitor (see Calbiochem publication Cleland's Reagent-A Current Bibliography).

RNase treatment, in the absence of DTT, however, does not completely eliminate polyribosomal aggregates consisting of two to four ribosomes (Fig. 1). RNase-resistant polyribosomes from Ascaris lumbricoides have been described (Kaulenas and Fairbairn, 1966). After preincubation with trypsin, these workers reported a complete breakdown of their material to monosomes. RNaseinsensitive, trypsin-sensitive polysomes have also been extracted from heart muscle of chick embryos (Rabinowitz et al., 1964). I have tried to disrupt Drosophila polyribosomes by using trypsin with and without subsequent RNase treatment, with no particular effect (Boshes, 1969).

Whitney et al. (1968) reported in an abstract the extraction of polysomes from Drosophila. These authors claimed that $0.1 \mathrm{M} \mathrm{K}^{+}$in their buffer provided an ionic environment which permitted thorough degradation of all RNP aggregates to monosomes; heterodisperse polysome profiles were converted to a monodisperse peak of approximately 80S. Martin et al. (1969) have demonstrated that ionic conditions similar to those in many polyribosome extraction buffers strongly influence dissociation and reaggregation of ribosomes and their subunits in eukaryotic material. Their observations might explain the persistence of di- and trisomes following RNase treatment of my preparations, since the buffer contains $10 \mathrm{~mm}$ $\mathrm{Mg}^{++}$.

RNA Isolated from Soluble and Membrane-Bound Polyribosomes

The difference in ratio between ribosomal RNA's recoverable from the soluble and membrane-bound polysomes has already been noted; a consistently higher ratio of 28S: 18S RNA was obtained from the membrane-bound population than from the soluble one. This observation cannot be attributed to degradation of the more extensively treated RNA since an opposite result, more $18 \mathrm{~S}$ relative to $28 \mathrm{~S}$, would be anticipated by breakdown of ribosomal RNA. Sabatini et al.
(1966) have reported the differential release of membrane-bound ribosomal subunits into the cell sap following EDTA treatment, the 40S RNP particle being more easily displaced than the $60 \mathrm{~S}$ particle in guinea pig hepatic microsomes. Vesco and Penman (1969) have also found an altered 28S:18S ratio in RNA extracted from a resuspended "mitochondrial pellet." They too attributed their unusual 28S:18S ratio, which was much higher than total cellular RNA, to be the result of selective loss of the $18 \mathrm{~S}$-containing ribosomal subunit from membranes in the presence of 0.001 м EDTA. Homogenization of Drosophila larvae with the Dounce grinder might have removed less firmly bound 18S-containing subunits from membranes. This partitioning artifact would account for the first $10,000 \mathrm{~g}$ supernatant's containing a low $28 \mathrm{~S}: 18 \mathrm{~S}$ ratio owing to contribution from 18S-containing subunits from the membrane fraction, whereas the membrane-containing fraction has a higher $28 \mathrm{~S}: 18 \mathrm{~S}$ ratio owing to the reciprocal absence of $18 \mathrm{~S}$-containing subunits. Alternatively, there may be more $18 \mathrm{~S}$-containing subunits normally circulating in the cytoplasm than 28S-containing subunits which are more tightly bound to the membrane. So far, these alternative hypotheses have not been critically tested.

\section{Isotope Incorporation into Larvae}

The procedure for inducing larvae to incorporate isotope in the presence of a feeding stimulant makes possible genuine short-term labeling studies in Drosophila. Unlike injections of individual animals this technique is limited by neither the size nor the number of treated individuals. In addition, one may anticipate that labeling the first or second instar larvae will have the same success that has been demonstrated with third instar larvae. After $25 \mathrm{~min}$, a short labeling period for metazoan tissue (Girard et al., 1965; Henshaw et al., 1965; Latham and Darnell, 1965), over 120,000 dpm/g larvae were incorporated into total cellular RNA. The specific activities of several of the fractions, particularly the $16-5 \mathrm{~S}$ heterogeneous RNA, indicate that even shorter incubations may be feasible.

\section{Analysis of Radioactive Labeling of $R N A$ Derived from Polyribosomes}

The results of radioactive precursor incorporation into ribosomal RNA's of both soluble and 
membrane-bound polyribosomal fractions are consistent with Greenberg's studies on total RNA labeling in D. virilis (1969): Drosophila behaves like HeLa cells with respect to $r$-RNA synthesis and processing (see Darnell, 1968, for review). Results similar to those described here have been demonstrated in comparable fractionation procedures utilizing a rat liver system (Hallinan and Munro, 1965) and rat spleen system (Talal and Kaltreider, 1968). These groups reported similar label distribution between soluble and membranebound populations, as well as a predominance of uridine incorporation into the $16-5 \mathrm{~S}$ region of RNA isolated from the soluble polyribosomal fraction. The noncoordinate appearance of $18 \mathrm{~S}$ and 28S molecules in the cytoplasm suggests that ribosomes normally circulate in the form of free subunits (Girard et al., 1965; Joklik and Becker, $1965 \mathrm{a}$ and $\mathrm{b}$ ). The accumulation of isotope in the ribosomal RNA peaks of both polyribosomal populations from Drosophila is consistent with this hypothesis. The 18S-containing subunit is rapidly exported, while the slowly labeling 28S-containing subunit does not reach the specific activity of the 18S r-RNA by 60 min (Figs. 3 and 4). Although the over-all specific activity of $r-R N A$ from the soluble polyribosomes is higher than that of $r-R N A$ from the membrane-bound fraction (Figs. 3 and 4), the rate at which the membrane-bound fraction equilibrates (equilibration is defined as specific activity of $28 \mathrm{~S} r-\mathrm{RNA}$ : specific activity of 18S $r$-RNA $=1$ ) is faster than the rate for the soluble one. These data can best be explained by assuming that a small part of the total membranebound ribosomal subunit population turns over more rapidly than does the soluble subunit population (see Boshes, 1969, for discussion).

The 28S r-RNA-component cosedimented with the $\mathrm{OD}_{254}$ peak from the time of its first appearance, $40 \mathrm{~min}$, indicating that it had been completely processed before exportation from the nucleolus (see Darnell, 1968, for review). The heterogeneous RNA fraction from the 16 to $5 \mathrm{~s}$ region of the soluble polysomes exhibited the highest specific activity throughout all time periods (Fig. 5). This region contains the size class of molecules thought to correspond to m-RNA molecules (Latham and Darnell, 1965; Brown and Gurdon, 1966).

The specific activities of the 16-5S region as well as the $18 \mathrm{~S}$ and $28 \mathrm{~S}$ r-RNA's from the membrane-bound population of polyribosomes were all lower than those of their respective populations from the soluble polyribosome fraction. On the other hand, the specific activity of the $4 \mathrm{~S}$ fraction from the membrane-bound population was practically identical to that of the 4S RNA recovered from the first $10,000 \mathrm{~g}$ supernatant, although the first supernatant contained most of the 4S RNA on the basis of the $\mathrm{OD}_{254}$ profile (Figs. 3-5). Since transfer RNA is a cytoplasmic component, one would anticipate that the bulk of it would appear in the first $10,000 \mathrm{~g}$ supernatant, the cell sap. The small amount of 4S RNA which appears in the second fraction probably represents the same population, on the basis of its parallel isotope incorporation. A small portion of this material may be t-RNA bound to membranebound polyribosomes. Trapping of soluble t-RNA by the sedimentable material of the homogenate may also account for some of the radioactivity in this region.

\section{Analysis of Amino Acid Incorporation into Polyribosomes}

The pattern of incorporation of leucine- ${ }^{3} \mathrm{H}$ into polyribosomes suggests the labeling of nascent proteins. Moreover, large aggregates appeared to have been isolated without substantial degradation (Fig. 6) since there was little radioactivity under the mono- and disome peaks where nascent peptides attached to degraded polysomal fragments would be expected to accumulate. These data are consistent with reports that the specific activity of amino acid incorporation increases throughout the dimer and trimer gradient retions, reaching a constant value in the area of larger polyribosomes ( $\mathrm{N}=4-7$ [Goldberg and Green, 1967]). The heavier aggregates therefore appear to constitute the majority of the actively synthesizing populations in Drosophila as in other metazoan cell types (see Goldberg and Green, 1967, for review).

Labeled 18 and 28S r-RNA's indicate that newly completed ribosomal subunits are present in the cytoplasm by 60 min (Figs. 3 and 4). It is plausible that some ribosomal proteins may have also been synthesized within that time. The absence of radioactivity under the monosome region, therefore, may indicate that newly fabricated ribosomal subunits first appear in both fractions in the polyribosome, not the monosome, population. The monosomes may represent older, dissociated polysomal aggregates. Similar arguments 
have been made for other eukaryotes (Girard et al., 1965; Joklik and Becker, 1965a; Darnell, 1968).

One aspect of the kinetic study of amino acid incorporation (Fig. 7) deserves elaboration. Radioactive leucine sediments in the first $10,000 \mathrm{~g}$ pellet but is later released by Triton X-100 treatment of this pellet and appears in the supernatant of the membrane-bound polysomal fraction. Such behavior would be predicted from porteins bound in membranes. Redman and Sabatini (1966a and b) proposed that secretory proteins are sequestered in sedimentable endoplasmic reticulum and are exported via this membrane-transport system. While Redman and Sabatini's microsomal fraction was derived from a $105,000 \mathrm{~g}$ pellet, Drosophila membrane-bound polyribosomes were isolated from a $10,000 \mathrm{~g}$ centrifugation. But this $10,000 \mathrm{~g}$ pellet from Drosophila did contain over $40 \%$ of the total ribosomal RNA; and electron microscopic examination revealed multiple polyribosomal aggregates bound to membranes (Boshes, 1969). Therefore, while the membranebound RNP fraction cannot be considered operationally identical to the microsomal preparation from guinea pig liver studied by Redman and Sabatini, the observed data seem to be best rationalized by an analogous argument.

\section{CONCLUSION}

Two populations of polyribosomes have been isolated in reproducible amounts from third instar larvae of Drosophila melanogaster. One is present in the cell sap, while the second appears to be membrane-bound. Both conform to physical criteria for polyribosomes: rapidly sedimenting RNP aggregates with peaks of absorbancy at $254 \mathrm{~m} \mu$ corresponding to multiple units of monosomes.

\section{REFERENCES}

Allfrey, V. 1959. The isolation of subcellular components. In The Gell, J. Brachet and A. E. Mirskey, editors. Academic Press Inc., New York. $1: 214$.

Bernhardt, D., and J. E. Darnell. 1969. t-RNA synthesis in HeLa cells : A precursor to t-RNA and the effects of methionine starvation on t-RNA synthesis. J. Mol. Biol. 42:43.

Boshes, R. 1969. An investigation of ribonucleoprotein metabolism in Drosophila melanogaster: I. Successful cell fractionation and isolation of poly-
Both are sensitive to mild ribonuclease digestion, which shifts the rapidly sedimenting polysomes to the region of the gradient where lighter RNP structures are found.

Short-term isotopic labeling of larvae with protein and nucleic acid precursors has been achieved by combining a feeding stimulant of dried yeast with mild dehydration of the larvae by filtration. A functional distinction between these soluble and membrane-bound polyribosomes has been demonstrated. The soluble population accumulates RNA precursors more rapidly than does the membrane-bound one while the latter exhibits a significantly higher rate of amino acid incorporation. The distribution of leucine ${ }^{-3} \mathrm{H}$ confirms that both populations of RNP are functional polyribosomes and not aggregation artifacts. Whether there be any functional relationship between soluble and membrane-bound polyribosomes, whether there be a unique set of proteins synthesized by the respective classes, or whether these represent RNP from differing cell populations all await further investigation.

I should like to acknowledge the guidance of Professor John L. Hubby who patiently supervised this research. I should like to thank Dr. David L. Kirk for many constructive discussions. Finally, I thank Dr. Martin Gorovsky for editorial assistance.

This work was supported by grant No. GM-11 216 from the National Institutes of Health, U. S. Public Health Service, to J. L. Hubby and is taken in part from a dissertation submitted to the University of Chicago, Department of Biology in partial fulfillment of the requirements for the degree of Doctor of Philosophy, March 1969. I was supported by National Institutes of Health U.S. Public Health Service Predoctoral Fellowship No. GM-19 939.

Received for publication 21 August 1969, and in revised form 30 April 1970.

ribosome populations with metabolic differences: II. Characterization of an experimental system with the potential of combining genetic with biochemical analysis. Doctorate Thesis. University of Chicago.

Brown, D. D., and J. B. Gurdon. 1966. Size distribution and stability of DNA-like RNA synthesized during development of anucleolate embryos of Xenopus laevis. J. Mol. Biol. 19:399.

Brown, D. D., and E. LrTtNA. 1964. Variations in the synthesis of stable RNA's during oogenesis 
and development of Xenopus laevis. J. Mol. Biol. 8:688.

Carpenter, J. M. 1950. A new semi-synthetic food medium for Drosophila. Drosophila Information Service. 24:96.

Church, R. B., and R. W. Robertson. 1966. A biochemical study of the growth of Drosophila melanogaster. J. Exp. Zool. 162:337.

Cooper, K. W. 1968. Freeing Drosophila of mold. Drosophila Information Service. 43:194.

Darnell, J. E. 1968. Ribonucleic acids from animal cells. Bacteriol. Rev. 32:262.

EPhrussi, B. 1942. Chemistry of "eye color hormones" of Drosophila. Quart. Rev. Biol. 17:327.

Girard, M., H. Latham, S. Penman, and J. E. DARNELL. 1965. Entrance of newly formed messenger RNA and ribosomes into HeLa cell cytoplasm. J. Mol. Biol. 11:187.

Golberg, G., and H. Green. 1967. Collagen synthesis on polyribosomes of cultured mammalian fibroblasts. J. Mol. Biol. 26:1.

GreenberG, J. R. 1969. Synthesis and properties of ribosomal RNA in Drosophila. J. Mol. Biol. 46:85.

Hallinan, T., and H. N. Munro. 1965. Protein synthesis and ribonucleic acid turnover in ratliver microsome subfractions. Biochim. Biophys. Acta. 108:285.

Hastings, J. R. B., and K. S. Kirby. 1966. The nucleic acids of Drosophila melanogaster. Biochem. $J$. 11:532.

HenNig, W. 1968. Ribonucleic acid synthesis of the Y-chromosome of Drosophlia hydei. J. Mol. Biol. 38:227.

Henshaw, E. C., M. Revel, and H. H. Hiatt. 1965. A cytoplasmic particle bearing messenger ribonucleic acid in rat liver. J. Mol. Biol. 14:241.

Horikawa, M., and A. Fox. 1964. Culture of embryonic cells of Drosophila melanogaster in vitro. Science (Washington). 145:1437.

JokLIK, W., and Y. Becker. 1965a. Studies on the genesis of polyribosomes: I. The origin and significance of the subribosomal particles. J. Mol. Biol. 13:496.

Joklik, W., and Y. Becker. 1965b. Studies on the genesis of polyribosomes: II. The association of nascent messenger RNA with the $40 \mathrm{~S}$ subribosomal particle. J. Mol. Biol. 13:511.

Kaulenas, M. S., and D. Fairbairn. 1966. Ribonuclease-stable polysomes in the egg of Ascaris lumbricoides. Develop. Biol. 14:481.

Latham, H., and J. E. Darnell. 1965. Distribution of m-RNA in the cytoplasmic polyribosomes of the HeLa cell. J. Mol. Biol. 14:1.

LoENing, U. E. 1968. Molecular weights of ribosomal RNA in relation to evolution. J. Mol. Biol. 38:355.
Martin, R. G., and B. N. Ames. A method for determining the sedimentation behavior of enzymes: Application to protein mixtures. J. Biol. Chem. 236:1372.

Martin, T. E., F. S. Rolleston, R. B. Low, and I. G. Wool. 1969. Dissociation and reassociation of skeletal muscle ribosomes. J. Mol. Biol. 42:135.

Noll, Hans. 1967. Characterization of macromolecules by constant velocity sedimentation in sucrose gradients. Nature (London). 215:360.

Palade, G. E. 1959. Microsomes and Ribonucleoprotein Particles In Microsomal Particles and Protein Synthesis. R. B. Roberts, editor. Pergamon Press Inc., New York. 36.

Penman, S. 1966. RNA metabolism in the HeLa cell nucleus. J. Mol. Biol. 17:117.

Rabinowitz, M., R. Zak, B. Beller, O. Rampersad, and I. G. Wool. 1964. Effect of proteolytic enzymes on sedimentation properties of ribonucleoprotein particles from heart muscle. Proc. Nat. Acad. Sci. U.S.A. 52:1353.

Redman, C., and D. D. Sabatini. 1966a. Transfer of peptides across microsomal membranes in vitro. Fed. Proc. 25:216.

Redman, C., and D. D. Sabatini. 1966b. Vectoral discharge of peptides released by puromycin from attached ribosomes. Proc. Nat. Acad. Sci. U.S.A. 56:608.

Rifkind, R. A., L. Luzzatto, and P. A. Marks. 1964. Size of polyribosomes in intact reticulocytes. Proc. Nat. Acad. Sci. U.S.A. 52:1227.

RitossA, F. M., and K. C. Atwood. 1966. Unequal proportions of DNA complementary to ribosomal RNA in males and females of Drosophila simulans. Proc. Nat. Acad. Sci. U.S.A. 56:496.

Ritossa, F. M., K. C. Atwood, and S. Spiegelman. 1966a. On the redundancy of DNA complementary to amino-acid transfer RNA and its absence from the nucleolar organizer region of Drosophila melanogaster. Genetics. 54:666.

Ritossa, F. M., K. C. Atwood, and S. Spiegelman. 1966b. A molecular explanation of the bobbed mutants of Drosophila as partial deficiencies of "ribosomal" DNA. Genetics. 54:819.

Ritossa, F. M., and S. Spiegelman. 1965. Localization of DNA complementary to ribosomal RNA in the nucleolus organizer region of Drosophila melanogaster. Proc. Nat. Acad. Sci. U.S.A. 53:737.

Sabatini, D. D., Y. TAshiro, and G. E. Palade. 1966. On the attachment of ribosomes to microsomal membranes. J. Mol. Biol. 19:503.

Siekevitz, P., and G. E. Palade. 1959. A cytochemical study on the pancreas of the guinea pig. IV. Chemical and metabolic investigation of the ribonucleoprotein particles. J. Biophys. Biochem. Cytol. 5:1.

R. A. Boshes Drosophila Polyribosomes 
Talal, N., and H. B. Kaltreider. 1968. Functional and structural studies of membrane-bound and free ribosomes from rat spleen. J. Biol. Chem. 243:6504.

Vesco, C., and S. Penman. 1969. The cytoplasmic RNA of HeLa cells: New discrete species associated with mitochrondria. Proc. Nat. Acad. Sci. U.S.A. 62:218.

WARNER, J. R., P. M. KNOPF, and A. Rich. 1963.
A multiple ribosomal structure in protein synthesis. Proc. Nat. Acad. Sci, U.S.A. 49:122.

Wettstein, F. O., T. Staehelin, and H. Noll. 1963. Ribosomal aggregate engaged in protein synthesis: Characterization of the ergosome. Nature (London). 197:430.

Whitney, J. B., G. W. Stafford, and J. C. Luchessi. 1968. The isolation of polysomes from Drosophila melanogaster and its bearing on RNase-resistant polysomes. J. Cell Biol. 39:142A. 